\title{
Solubilização de fosfatos naturais por microrganismos isolados de cultivos de Pinus e Eucalyptus de Santa Catarina ${ }^{(1)}$
}

\author{
Germano Nunes Silva Filho(2), Charles Narloch ${ }^{(2)}$ e Rosana Scharf(2)
}

\begin{abstract}
Resumo - A utilização de microrganismos solubilizadores tem sido sugerida como alternativa ao uso de fertilizantes fosfáticos. Para serem utilizados num programa de inoculação controlada, os microrganismos devem apresentar grande capacidade e potencial de solubilização. O objetivo deste trabalho foi avaliar a capacidade e o potencial de solubilização de 56 isolados inoculados em meio GES contendo fosfato (Anitápolis, Araxá ou Catalão), usando-se um fatorial 57x3 (56 isolados + testemunha e três fosfatos) conduzido em delineamento completamente casualizado com três repetições. Após 15 dias de incubação, determinaram-se as quantidades de $\mathrm{P}$ e o pH do meio. Foram verificados efeitos dos fosfatos, dos isolados e da interação. Baixos valores de $\mathrm{pH}$ foram obtidos por isolados que apresentaram médio a alto potencial. $\mathrm{O}$ teor médio de $\mathrm{P}$ foi superior no fosfato de Anitápolis, seguido do Araxá. Trinta e um isolados solubilizaram quantidades significativas. O 310 apresentou o mais alto potencial (média de $263 \mu \mathrm{g} \mathrm{mL} \mathrm{m}^{-1} \mathrm{de}$ P). Quatro isolados (177, 262, 251 e 269$)$ apresentaram alto potencial (120 a $\left.150 \mu \mathrm{g}\right)$, e doze $(201,309,199,195,249,202,198,305,253,196,203$ e 307), mostraram valores médios (80 a $120 \mu \mathrm{g})$. O comportamento dos isolados foi diferente entre os fosfatos. Apenas quatro isolados solubilizaram os três fosfatos $(310,251,199$ e 249). As características apresentadas pelos isolados 310, 251, 199 e 249 os qualificam para um programa de seleção visando à inoculação controlada.
\end{abstract}

Termos para indexação: solubilizadores de fosfato, fósforo, biologia de solo.

\section{Solubilization of natural phosphates by microorganisms isolated from Pinus and Eucalyptus plantations in Santa Catarina, Brazil}

\begin{abstract}
The use of P-solubilizing microorganisms have been suggested as an alternative to replace the utilization of phosphate fertilizers. In order to be used in programs of controlled inoculation, microorganisms must display a high capacity and potential for solubilization. The aim of this study was to evaluate the potential and the capacity of 56 microbial isolates to solubilize different types of phosphates. The evaluation was performed in GES medium supplemented with one of the following phosphates: Anitápolis, Araxá and Catalão, through a factorial experiment [(56 isolates + control $) \mathrm{x}$ three phosphates] in a randomized complete design with three replications. After 15 days of inoculation, levels of phosphorus and $\mathrm{pH}$ of the media were determined. Effects of phosphates, isolates and the interaction were verified. Low values of $\mathrm{pH}$ were obtained by isolates with high and medium potential. The average level of $\mathrm{P}$ was superior in Anitápolis phosphate, followed by Araxá. Thirty-one isolates solubilized significant quantities. The isolate 310 showed the highest potential (average of $263 \mu \mathrm{g} \mathrm{mL}^{-1}$ of P). Four isolates (177, 262, 252 and 269) showed high potential (120 to $150 \mu \mathrm{g}$ ), and twelve $(201,309,199,195,249,202,198,305,253,196,203$ and 307) showed medium values (80 to $120 \mu \mathrm{g})$. Isolates behavior was different among phosphates. Only four isolates solubilized all three phosphates (310, 251, 199 and 249). The characteristics displayed by isolates 310, 251, 199 and 249 qualified them for a screening program aiming controlled inoculation.
\end{abstract}

Index terms: phosphate-solubilizing microorganism, phosphorus, soil biology.

(1) Aceito para publicação em 14 de novembro de 2001 . Projeto financiado pela International Foundation for Science.
(2) Universidade Federal de Santa Catarina, Dep. de Microbiologia e Parasitologia, Centro de Ciências Biológicas, Caixa Postal 476, CEP 88010-970 Florianópolis, SC. E-mail: germano@ccb.ufsc.br, charles@narloch.com 


\section{Introdução}

O setor florestal constitui um importante segmento econômico do País, pois contribui com 3,3 bilhões de dólares em exportação (Hoeflich et al., 2000) e 4\% do Produto Interno Bruto (Brasil, 2000). O Estado de Santa Catarina destaca-se no cenário nacional na produção de papel e celulose, e apresenta 5\% de sua superfície coberta por reflorestamentos, especialmente com Pinus e Eucalyptus (Brandão, 1997). Em face das restrições espaciais e ecológicas ao aumento da produção por expansão da área cultivada, as atenções estão voltadas para o aumento da produtividade.

Um dos fatores que afetam o crescimento vegetal é a disponibilidade de nutrientes, notadamente, no caso dos solos brasileiros, a de fósforo (P). Para suprir essa carência, são utilizados fosfatos solúveis em dosagens superiores às necessidades das culturas, pois a maior parte do $\mathrm{P}$ aplicado ao solo não é prontamente disponível às plantas. Embora o Brasil apresente inúmeras reservas, o uso de fosfatos naturais é reduzido. O custo de produção é menor, mas a solubilidade é baixa, o que diminui sua eficiência (Braga et al., 1991), e restringe o seu uso a áreas próximas ao local de beneficiamento e a determinadas culturas.

No solo, o P é sujeito a inúmeros processos biogeoquímicos que alteram sua disponibilidade. Entre esses processos, destaca-se a dissolução de fosfatos, que os torna disponíveis para as plantas (Whitelaw, 2000). Diversos microrganismos do solo, incluindo bactérias e fungos, possuem capacidade para solubilizar fosfatos por meio de diferentes mecanismos, especialmente pela produção de ácidos (Sperber, 1958; Banik \& Dey, 1982; Kucey, 1983; Nahas, 1999; Rodrígez \& Fraga, 1999; Silva Filho \& Vidor, 2000; Whitelaw, 2000). A inoculação de microrganismos solubilizadores de fosfatos ou o manejo de suas populações têm sido sugeridos como forma de substituir ou diminuir o uso de fertilizantes fosfáticos solúveis, mediante um melhor aproveitamento dos fosfatos naturais existentes ou adicionados ao solo e dos formados pela aplicação de fontes solúveis (Goldstein, 1986; Kim et al., 1998). Para serem utilizados num programa de inoculação controlada, os microrganismos devem apresentar, entre outras características, grande capacidade e alto po- tencial de solubilização de fosfatos, ou seja: devem solubilizar vários tipos de fosfatos, e a solubilização deve ser de alta intensidade.

O presente trabalho teve por objetivo avaliar a capacidade e o potencial de 56 isolados de microrganismos de solubilizar fosfatos naturais.

\section{Material e Métodos}

Cinqüenta e seis isolados de microrganismos solubilizadores de fosfatos, bactérias e fungos, obtidos de substrato, solo ou rizosfera de cultivos em sementeiras ou florestas de Pinus ou Eucalyptus do Estado de Santa Catarina (Tabela 1) foram inoculados em frascos de $100 \mathrm{~mL}$ contendo $50 \mathrm{~mL}$ de meio Glicose Extrato de Solo (GES) (Sylvester-Bradley et al., 1982) e 0,25 g do fosfato natural de Anitápolis, Araxá ou Catalão, moído e peneirado em malha de $0,053 \mathrm{~mm}$. Os teores $\mathrm{P}_{2} \mathrm{O}_{5}$ total e solúvel em ácido cítrico (2\%) foram de $9,4 \%$ e $4,3 \%$; $9,3 \%$ e $3,2 \%$; 9,4\% e $2,5 \%$, respectivamente, no fosfato de Araxá, Anitápolis e Catalão, respectivamente. As análises foram realizadas pelo Laboratório Físico Químico e Biológico da Companhia Integrada de Desenvolvimento de Santa Catarina. Como inóculo foram utilizadas culturas com 48 horas de incubação. Para as bactérias utilizou-se $1 \mathrm{~mL}$ de cultura líquida, e para os fungos, um disco de $4 \mathrm{~mm}$ de diâmetro, retirado da borda da colônia crescida em meio sólido.

Após um período de 15 dias de incubação à temperatura de $30^{\circ} \mathrm{C}$, o meio GES foi centrifugado a $3.000 \mathrm{rpm} \mathrm{du}-$ rante 15 minutos. Em seguida, o sobrenadante foi utilizado na determinação de $\mathrm{P}$ e $\mathrm{pH}$. O P solúvel no extrato foi avaliado por espectrofotometria a $660 \mathrm{~nm}$, segundo procedimento descrito por Tedesco et al. (1995).

O experimento constituiu-se de um fatorial [(56 isolados + testemunha) $x$ três fosfatos] conduzido em delineamento completamente casualizado com três repetições, e as médias foram comparadas pelo teste de Tukey a 5\%.

\section{Resultados e Discussão}

Os teores de $\mathrm{P}$ presentes no meio GES após a incubação foram superiores no fosfato de Anitápolis, seguidos do fosfato de Araxá, e, por último, do de Catalão (Tabela 2). Estas diferenças provavelmente estão relacionadas à composição do fosfato, como o teor de $\mathrm{CO}_{2}$ (Alcarde \& Ponchio, 1983), e, ou, à presença de nutrientes inorgânicos que acompanham o produto. Diferenças na disponibilização de fosfatos têm sido verificadas no solo e em meios de cultura (Oliveira et al., 1984; Silva Filho \& Vidor, 2000). 
Tabela 1. Procedência e classificação dos isolados de microrganismos solubilizadores de fosfatos obtidos de cultivos de Pinus e Eucalyptus de Santa Catarina.

\begin{tabular}{|c|c|c|c|c|c|}
\hline Isolados & Local & Espécie vegetal & Condição & Amostra & Classificação \\
\hline 119 & Mafra, SC & Eucalyptus sp. & Floresta & $\mathrm{S}^{(1)}$ & Aspergillus \\
\hline 133 & Mafra, SC & Pinus sp. & Floresta & $\mathrm{S}$ & Penicillium \\
\hline 138 & Mafra, SC & Pinus sp. & Floresta & $\mathrm{S}$ & Penicillium \\
\hline 139 & Mafra, SC & Eucalyptus sp. & Floresta & $\mathrm{S}$ & Penicillium \\
\hline 141 & Mafra, SC & Pinus sp. & Floresta & $\mathrm{S}$ & Penicillium \\
\hline 142 & Mafra, SC & Eucalyptus sp. & Floresta & $\mathrm{S}$ & Aspergillus \\
\hline 148 & Massaranduba, SC & E. grandis & Viveiro - 120 dias & $\mathrm{R}^{(2)}$ & Pseudomonas \\
\hline 154 & Três Barras, SC & E. dunnii & Viveiro - 15 dias & $\mathrm{R}$ & Enterobacteriaceae \\
\hline 155 & Barra do Sul, SC & P. elliotti & Floresta - 10 anos & $\mathrm{S}$ & $-(3)$ \\
\hline 175 & Três Barras, SC & E. dunnii & Viveiro - 90 dias & $\mathrm{S}$ & - \\
\hline 177 & Três Barras, SC & E. dunnii & Viveiro - 75 dias & $\mathrm{R}$ & Penicillium \\
\hline 185 & Massaranduba, SC & E. grandis & Floresta - 9 anos & $\mathrm{R}$ & Enterobacteriaceae \\
\hline 189 & Três Barras, SC & P. taeda & Viveiro - 50 dias & $\mathrm{R}$ & Enterobacteriaceae \\
\hline 190 & Três Barras, SC & E. dunnii & Viveiro - 60 dias & $\mathrm{S}$ & Penicillium \\
\hline 191 & Três Barras, SC & E. dunnii & Viveiro - 60 dias & $\mathrm{S}$ & Rhizopus \\
\hline 192 & Correia Pinto, SC & P. taeda & Viveiro - 60 dias & $\mathrm{S}$ & Penicillium \\
\hline 195 & Correia Pinto, SC & P. taeda & Floresta - 29 anos & $\mathrm{R}$ & Aspergillus \\
\hline 196 & Massaranduba, SC & E. grandis & Floresta - 5 anos & $\mathrm{R}$ & Aspergillus \\
\hline 198 & Correia Pinto, SC & P. taeda & Floresta - 20 anos & $\mathrm{S}$ & Aspergillus \\
\hline 199 & Três Barras, SC & P. taeda & Floresta - 1 ano & $\mathrm{S}$ & Aspergillus \\
\hline 200 & Três Barras, SC & P. taeda & Floresta - 10 anos & $\mathrm{R}$ & Aspergillus \\
\hline 201 & Três Barras, SC & E. dunnii & Floresta - 3 anos & $\mathrm{S}$ & Aspergillus \\
\hline 202 & Três Barras, SC & E. dunnii & Floresta - 5 anos & $\mathrm{S}$ & Bastonete Gram + \\
\hline 203 & Três Barras, SC & E. dunnii & Floresta - 5 anos & $\mathrm{S}$ & - \\
\hline 205 & Mafra, SC & E. dunnii & Floresta - 5 anos & $\mathrm{S}$ & Bastonete Gram + \\
\hline 215 & Três Barras, SC & E. dunnii & Viveiro - 90 dias & $\mathrm{S}$ & - \\
\hline 221 & Três Barras, SC & P. taeda & Floresta - 1 ano & $\mathrm{R}$ & Pseudomonas \\
\hline 222 & Três Barras, SC & P. taeda & Floresta - 1 ano & $\mathrm{R}$ & Enterobacteriaceae \\
\hline 233 & Ilhota, SC & E. grandis & Floresta - 2 anos & $\mathrm{S}$ & Penicillium \\
\hline 238 & Massaranduba, SC & E. grandis & Floresta - 9 anos & $\mathrm{R}$ & Penicillium \\
\hline 239 & Correia Pinto, SC & P. taeda & Viveiro - 90 dias & $\mathrm{R}$ & Bacillus \\
\hline 240 & Três Barras, SC & E. dunnii & Floresta - 9 anos & $\mathrm{R}$ & Pseudomonas \\
\hline 249 & Três Barras, SC & Eucalyptus sp. & Floresta - 2 anos & $\mathrm{S}$ & Aspergillus \\
\hline 250 & Massaranduba, SC & E. grandis & Viveiro & $\mathrm{S}$ & Aspergillus \\
\hline 251 & Massaranduba, SC & P. elliotti & Floresta - 10 anos & $\mathrm{S}$ & Aspergillus \\
\hline 253 & Três Barras, SC & Pinus sp. & Floresta - 2 anos & $\mathrm{S}$ & - \\
\hline 261 & Três Barras, SC & P. taeda & Viveiro - Semeadura & $\mathrm{R}$ & Penicillium \\
\hline 262 & Massaranduba, SC & E. grandis & Viveiro - 45 dias & $\mathrm{S}$ & Penicillium \\
\hline 263 & Três Barras, SC & P. taeda & Viveiro - 120 dias & $\mathrm{S}$ & Penicillium \\
\hline 264 & Três Barras, SC & P. taeda & Viveiro & - & Penicillium \\
\hline 269 & Três Barras, SC & E. dunnii & Floresta - 9 anos & $\mathrm{S}$ & Penicillium \\
\hline 282 & Três Barras, SC & Pinus sp. & Viveiro - 150 dias & $\mathrm{R}$ & - \\
\hline 290 & Correia Pinto, SC & E. viminalis & Floresta - 19 anos & $\mathrm{R}$ & - \\
\hline 291 & Três Barras, SC & E. dunnii & Floresta - 9 anos & $\mathrm{S}$ & - \\
\hline 295 & Correia Pinto, SC & P. taeda & Floresta - 29 anos & $\mathrm{S}$ & Enterobacteriaceae \\
\hline 297 & Três Barras, SC & E. dunnii & Floresta - 9 anos & $\mathrm{S}$ & Enterobacteriaceae \\
\hline 300 & Barra do Sul, SC & P. elliotti & Floresta - 10 anos & $\mathrm{S}$ & Penicillium \\
\hline 301 & Massaranduba, SC & E. grandis & Viveiro - 105 dias & $\mathrm{S}$ & Penicillium \\
\hline 302 & Correia Pinto, SC & E. viminalis & Floresta - 19 anos & $\mathrm{R}$ & Penicillium \\
\hline
\end{tabular}

Continua... 
Tabela 1. Continuação.

\begin{tabular}{clllcl}
\hline Isolados & Local & Espécie vegetal & Condição & Amostra & Classificação \\
\hline 303 & Correia Pinto, SC & P. taeda & Viveiro - 240 dias & $\mathrm{S}$ & Penicillium \\
305 & Correia Pinto, SC & P. taeda & Viveiro - 240 dias & $\mathrm{S}$ & Aspergillus \\
306 & Barra do Sul, SC & P. elliotti & Floresta - 10 anos & $\mathrm{R}$ & Rhizopus \\
307 & Correia Pinto, SC & E. viminalis & Floresta - 19 anos & $\mathrm{S}$ & Aspergillus \\
308 & Três Barras, SC & P. taeda & Floresta - 15 anos & $\mathrm{R}$ & Aspergillus \\
309 & Três Barras, SC & E. dunnii & Floresta - 9 anos & $\mathrm{R}$ & Aspergillus \\
310 & Três Barras, SC & E. dunnii & Floresta - 9 anos & $\mathrm{S}$ & Aspergillus \\
\hline
\end{tabular}

(1)Solo. ${ }^{(2)}$ Solo rizosférico. ${ }^{(3)}$ Sem informação.

Dos 56 isolados testados, 31 solubilizaram quantidades significativas de fosfato (Tabela 2). Desses, o 310 apresentou o maior potencial de solubilização, com valor médio superior a $260 \mu \mathrm{g} \mathrm{mL}^{-1}$ de $\mathrm{P}$ de meio GES. Quatro isolados (177, 262, 251 e 269) apresentaram alto potencial, com valores variando de 120 a $150 \mu \mathrm{g} \mathrm{mL}^{-1}$ de $\mathrm{P}$, doze $(201,309,199,195,249,202$, 198, 305, 253, 196, 203 e 307) apresentaram valores considerados como médios ( 80 a $120 \mu \mathrm{g} \mathrm{mL}^{-1}$ de $\left.\mathrm{P}\right) \mathrm{e}$ quatorze apresentaram valores baixos $\left(40 \mathrm{a} 80 \mu \mathrm{g} \mathrm{mL}^{-1}\right.$ de P). Vinte e cinco isolados, representando $45 \%$ do total, apresentaram teores de $\mathrm{P}$ no meio GES estatisticamente semelhantes aos da testemunha não-inoculada. Variação no potencial de solubilização de microrganismos tem sido observada por vários autores, e é utilizada como uma das principais características no processo de seleção (Illmer \& Schinner, 1992; Mikanová \& Kubát, 1994; Silva Filho \& Vidor, 2000).

Entre os grupos de microrganismos, destacaramse os isolados fúngicos, com predomínio do gênero Aspergillus, seguido pelo gênero Penicillium. Esses gêneros estão entre os mais citados na literatura. No entanto, em relação a sua eficiência, existem controvérsias. Banik \& Dey (1982) avaliando diversos isolados de microrganismos solubilizadores verificaram que dois fungos do gênero Aspergillus foram os mais eficientes. Nahas (1996), trabalhando com isolados de outras procedências, verificou que os mais eficientes foram os do gênero Penicillium. O meio de cultura é um fator decisivo dessa característica. Silva Filho \& Vidor (2000), trabalhando em meio sólido, verificaram que o potencial de solubilização destes mesmos isolados era maior no gênero Penicillium.
Os isolados diferiram entre si, tanto na capacidade quanto na intensidade (potencial) de solubilização dos fosfatos. Vinte e seis isolados solubilizaram fosfato de Anitápolis, contra 24 de Araxá, e apenas seis de Catalão. Na maioria dos isolados, as quantidades de $\mathrm{P}$ solubilizadas no fosfato de Anitápolis foram superiores às do fosfato de Araxá e principalmente às do fosfato de Catalão. Em cerca de 10\% dos isolados $(201,253,309,200$ e 250$)$, as quantidades solubilizadas no fosfato de Araxá foram superiores às apresentadas no fosfato de Anitápolis. Nenhum isolado solubilizou maior quantidade de $\mathrm{P}$ no fosfato de Catalão do que no de Anitápolis, e apenas um (305) solubilizou mais no fosfato de Catalão do que no de Araxá.

Alguns isolados solubilizaram somente um tipo de fosfato. Isto ocorreu com sete isolados no fosfato de Anitápolis (238, 240, 221, 264, 189, 306 e 262) e quatro no fosfato de Araxá $(309,190,233$ e 300). Outros solubilizaram dois tipos de fosfatos. Quatorze solubilizaram fosfato de Anitápolis e de Araxá (177, 269, 201, 195, 202, 198, 253, 196, 203, 307, 191,308, 301 e 303); um, fosfato de Anitápolis e de Catalão (305); e um, fosfato de Araxá e de Catalão (250). Apenas quatro isolados solubilizaram os três fosfatos (310, 251, 199 e 249). Entre estes, apenas o isolado 249 solubilizou quantidades semelhantes em todos os fosfatos.

Resultados semelhantes foram obtidos por Lapeyrie et al. (1991), que verificaram que o potencial de solubilização variou com os isolados de Paxillus involutus, e Storkánová et al. (1999) e Mikanová \& Kubát (1994), com espécies de Rhizobium e Bradyrhizobium. Diferenças entre as fontes de fosfato com o mesmo microrganismo foram verifica- 


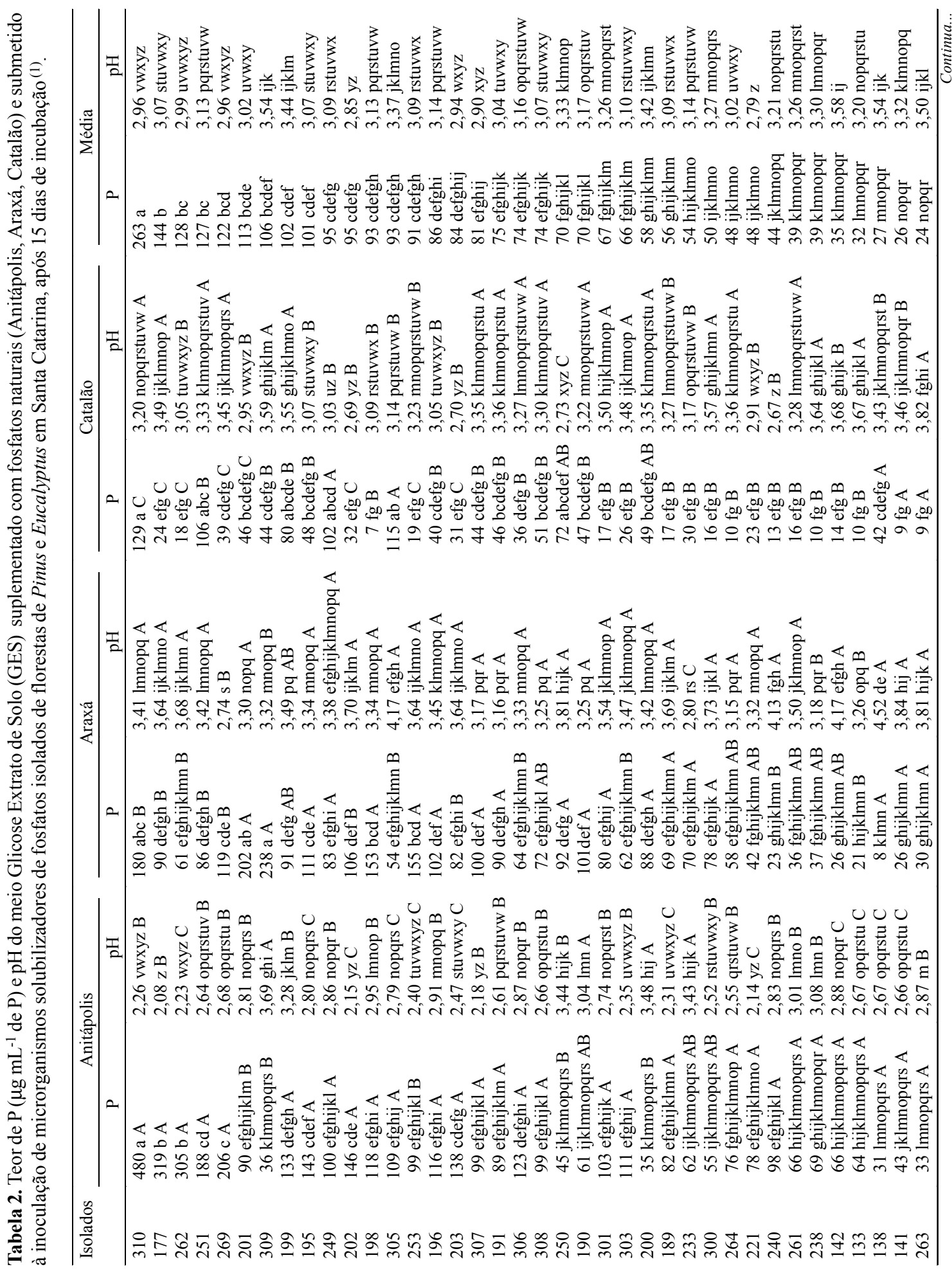




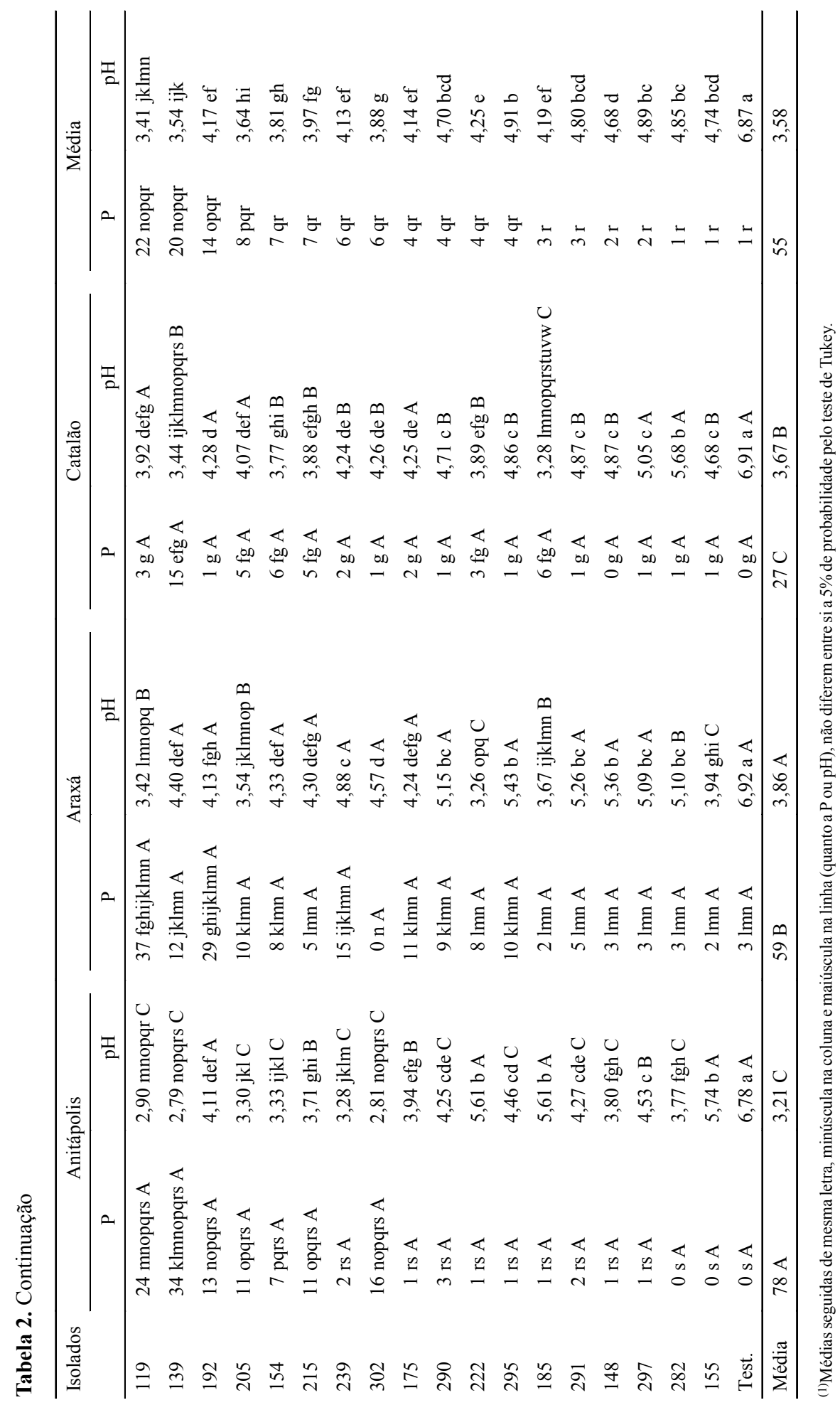


das por Nahas \& Assis (1992), Whitelaw et al. (1999), e Silva Filho \& Vidor (2000), e interações entre fontes e microrganismos foram encontradas por Lapeyrie et al. (1991), Nahas (1996) e Silva Filho \& Vidor (2000).

Não houve relação entre as procedências dos isolados e sua eficiência (Tabelas 1 e 2). Assim, não se observou predomínio de isolados mais eficientes entre os obtidos de rizosfera, como foi sugerido por Sperber (1958). Com relação à planta, embora entre os isolados com maior potencial de solubilização (310, $177,262,251$ e 269) haja um predomínio dos obtidos de Eucalyptus, particularmente de E. dunnii, isto não indica relação direta da fonte de isolamento e o potencial, uma vez que da mesma procedência ocorrem isolados com baixa capacidade de solubilização (297, 291, 215 e 154).

Todos os isolados diminuíram o $\mathrm{pH}$ do meio durante o cultivo (Tabela 2). As menores alterações ocorreram com os isolados 295, 297, 282, 291, 155 e 290. Os menores valores de $\mathrm{pH}$ foram obtidos nos meios submetidos à inoculação dos isolados 221 , $202,307,203,310,269$ e 262 . Nenhum dos primeiros solubilizou quantidades significativas de $\mathrm{P}$, e entre os últimos, estão os de médio a alto potencial de solubilização. Isto sugere um efeito da produção de ácidos na solubilização dos fosfatos (Sperber, 1958; Illmer et al., 1995; Nahas, 1996; Whitelaw et al., 1999), o que é confirmado pela análise de correlação entre o $\mathrm{pH}$ e o teor de $\mathrm{P}$ no meio $\left(\mathrm{r}=-0,54^{* *}\right)$. No entanto, este não deve ser o único mecanismo utilizado, uma vez que o coeficiente de determinação linear $\left(\mathrm{R}^{2}\right)$ foi de 0,294 , indicando, assim, que a diminuição do $\mathrm{pH}$ do meio de cultura foi responsável por $29,4 \%$ do aumento linear do P solubilizado (Illmer \& Schinner, 1992; Mikanová \& Kubát, 1994; Illmer et al., 1995). Vários fatores podem ter afetado esta relação; entre eles, as quantidades de $\mathrm{P}$ imobilizadas pelos microrganismos durante o crescimento. Outros fatores, como o tipo de fosfato e a interação deste com os isolados, também podem contribuir na relação. Embora a média de P no meio com fosfato de Araxá tenha sido superior à média no meio com fosfato de Catalão, a acidez foi menor. Os efeitos da interação ficam claros quando se comparam, por exemplo, os isolados 269, 309, 199 e 191 com os isolados 201, 202, 198 e 253.

\section{Conclusões}

1. A produção de ácidos é um dos mecanismos utilizados pelos microrganismos na solubilização de fosfatos naturais.

2. Não há relação entre a solubilização e a procedência dos isolados.

3. Fungos dos gêneros Aspergillus e Penicillium têm maior capacidade e potencial para a solubilização de fosfatos naturais.

4. A capacidade e o potencial de solubilização dos isolados 310, 251, 199 e 249 os tornam aptos a participarem de um programa de seleção visando à inoculação controlada.

\section{Referências}

ALCARDE, J. C.; PONCHIO, C. O. Conteúdo de "carbonato ligado" em fosfatos naturais brasileiros. Revista Brasileira de Ciência do Solo, Campinas, v. 7, p. 341343, 1983.

BANIK, S.; DEY, B. K. Available phosphate content of an alluvial soil as influenced by inoculation of some isolated phosphate-solubilizing microorganisms. Plant and Soil, The Hague, v. 69, n. 3, p. 353-364, 1982.

BRAGA， N. R.; MASCARENHAS, H. A. A.; BULISANI, E. A.; RAIJ, B. van; FEITOSA, C. T.; HIROCE, R. Eficiência agronômica de nove fosfatos em quatro cultivos consecutivos de soja. Revista Brasileira de Ciência do Solo, Campinas, v. 15, n. 3, p. 315-319, 1991.

BRANDÃO, L. G. Desafio florestal brasileiro. Silvicultura, São Paulo, v. 73, p. 23-29, 1997.

BRASIL. Ministério do Meio Ambiente. Programa nacional de florestas. Brasília, 2000. Disponível em: http://www.mma.gov.br/port/sbf/pnf/politica.html. Acesso em: set. 2000.

GOLDSTEIN, A. H. Bacterial solubilization of mineral phosphates: historical perspective and future prospects. American Journal of Alternative Agriculture, Greenbelt, v. 1, n. 2, p. 51-57, 1986.

HOEFLICH, V. A.; SCHAITZA, E. G.; MATTOS, P. P. Pesquisa florestal no Brasil: uma visão preliminar. Brasília: Instituto de Pesquisas Florestais, 2000. Disponível em: http://www. ipef.br. Acesso em: set. 2000. 
ILLMER, P.; BARBATO, A.; SCHINNER, F. Solubilization of hardly-soluble $\mathrm{AlPO}_{4}$ with $\mathrm{P}$-solubilizing microorganisms. Soil Biology and Biochemistry, Oxford, v. 27, n. 3, p. 265-270, 1995.

ILLMER, P.; SCHINNER, F. Solubilization of inorganic phosphates by microorganisms isolated from forest soils. Soil Biology and Biochemistry, Oxford, v. 24, n. 4, p. 389-395, 1992.

KIM, K. Y.; JORDAN, D.; McDONALD, G. A. Effect of phosphate-solubilizing bacteria and vesicular-arbuscular mycorrhizae on tomato growth and soil microbial activity. Biology and Fertility of Soils, Berlin, v. 26, p. 79-87, 1998.

KUCEY, R. M. N. Phosphate-solubilizing bacteria and fungi in various cultivated and virgin Alberta soils. Canadian Journal of Soil Science, Ottawa, v. 63, n. 4, p. 671-678, 1983.

LAPEYRIE, F.; RANGER, J.; VAIRELLES, D. Phosphate solubilizing activity of ectomycorrhizal fungi in vitro. Canadian Journal of Botany, Ottawa, v. 69, n. 2, p. 342 346, 1991.

MIKANOVÁ, O.; KUBÁT, J. Phosphorus solubilization from hardly soluble phosphates by soil microflora. Rostlinná Výroba, Prague, v. 40, n. 9, p. 833-840, 1994.

NAHAS, E. Factors determining rock phosphate solubilization by microrganisms isolated from soil. World Journal of Microbiology and Biotechnology, Oxford, v. 12 , n. 6 , p. 567-572, 1996.

NAHAS, E. Solubilização microbiana de fosfatos e de outros elementos. In: SIQUEIRA, J. O.; MOREIRA, F. M. S.; LOPES, A. S.; GUILHERME, L. R. G.; FAQUIN, U.; FURTINI NETO, A. E.; CARVALHO, J. G. (Ed.). Inter-relação fertilidade, biologia do solo e nutrição de plantas. Viçosa, MG: Sociedade Brasileira de Ciência do Solo/Ufla, 1999. p. 467-486.

NAHAS, E.; ASSIS, L. C. Efeito da concentração de fosfato na solubilização de fluorapatita por Aspergillus niger. Revista de Microbiologia, São Paulo, v. 23, n. 1, p. $37-$ 42, 1992.
OLIVEIRA, E. L. de; MUZILli, O.; IGUE, K.; TORNERO, M. T. T. Avaliação da eficiência agronômica de fosfatos naturais. Revista Brasileira de Ciência do Solo, Campinas, v. 8, n. 1, p. 63-67, 1984.

RODRÍGEZ, H.; FRAGA, R. Phosphate solubilizing bacteria and their role in plant growth promotion. Biotechnology Advances, New York, v. 17, p. 319-339, 1999.

SILVA FILHO, G. N.; VIDOR, C. Solubilização de fosfatos por microrganismos na presença de fontes de carbono. Revista Brasileira de Ciência do Solo, Viçosa, MG, v. 24, n. 2, p. 311-329, 2000.

SPERBER, J. I. The incidence of apatite-solubilizing organisms in the rhizosphere and soil. Australian Journal of Agricultural Research, Melbourne, v. 9, n. 6, p. 778$781,1958$.

STORKÁNOVÁ, G.; VORÍSEK, K.; MIKANOVÀ, O.; RANDOVÁ, D. P-solubilization activity of Rhizobium species strains. Rostlinná Výroba, Prague, v. 45, n. 9 , p. 403-406, 1999.

SYLVESTER-BRADLEY， R.; ASAKAWA， N.; LA TORRACA, S.; MAGALHÃES, F. M. M.; OLIVEIRA, L. A.; PEREIRA, R. M. Levantamento quantitativo de microrganismos solubilizadores de fosfatos na rizosfera de gramíneas e leguminosas forrageiras na Amazônia. Acta Amazonica, Manaus, v. 12, n. 1, p. 15-22, 1982.

TEDESCO, M. J.; GIANELLO, C.; BISSANI, C. A.; BOHNEN, H.; VOLKWEIS, S. J. Análise do solo, plantas e outros materiais. Porto Alegre: UFRGS, 1995. $174 \mathrm{p}$.

WHITELAW, M. A. Growth promotion of plant inoculated with phosphate-solubilizing fungi. Advances in Agronomy, New York, v. 69, p. 99-151, 2000.

WHITELAW, M. A.; HARDEN, T. J.; HELYAR, K. R. Phosphate solubilization in solution culture by the soil fungus Penicillium radicum. Soil Biology and Biochemistry, Oxford, v. 31, p. 655-665, 1999. 